\title{
The role of content marketing in social media content communities
}

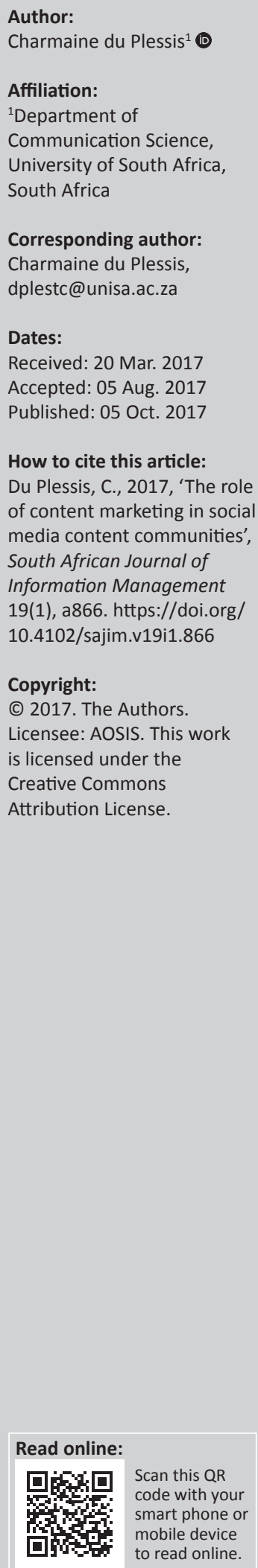

Background: Content marketing has become a leading marketing technique in digital marketing communication and uses the point of view of consumers to build relationships by creating and sharing engaging content in social media that enhance their daily lives. Existing research on social media communities has focused mainly on social media marketing and virtual brand community perspectives while content marketing's valuable and unobtrusive role in social media content communities has largely been overlooked.

Objective: The purpose of this article was to investigate content marketing's role in social media content communities to engage with the target audience in an innate manner.

Method: This study made use of a directed, inductive content analysis of 51 practitioner documents relating to business-to-consumer content marketing practices to add another perspective to existing research on communities in social media. The content analysis was facilitated by using QDA Miner, a widely adopted and reliable qualitative data analysis software programme.

Results: Three categories emerged from the data namely building content communities, platform-specific content and understanding channels. These categories provide sufficient evidence of how brands make use of social media content communities to connect with the target audience in an unobtrusive manner, in addition to being present in virtual brand communities.

Conclusion: The findings make several contributions to the existing literature. Firstly, it provides a clearer distinction between brand and social media content communities. Secondly, it extends conceptions about social media communities to include content communities and, thirdly, it provides sufficient evidence of how content marketing could benefit a brand by naturally becoming part of social media conversations.

\section{Introduction}

Social media has become imperative for branding because of the brand's ability to connect with consumers in a more interactive and individualised manner. Brands thus have a growing interest in social media-based brand communities to cultivate relationships with consumers through community building activities. Brand researchers concur that community building in social media leads to more brand loyalty and trust, although there are still different perspectives on how to achieve it (Laroche, Habibi \& Richard 2013). Consequently, there are ample studies on diverse brand community topics through lenses such as virtual brand communities (Potgieter \& Naidoo 2017; Rosenthal \& Brito 2017), social media marketing (Cawsey \& Rowley 2016) and consumers' reasons for joining brand communities in social media (Chi 2011).

Fewer studies focus on social media content communities whose main purpose is to share content in various formats among users (Kaplan \& Haenlein 2010). Recently, social media content communities have become more prominent because of brands that use content marketing as a branding technique. Content marketing is a contemporary marketing paradigm with many long term benefits such as building brand loyalty by engaging with the target audience with valuable content without employing promotional techniques (Pulizzi 2012b). However, more clarity is needed about the role of content marketing in social media content communities, especially because content marketing is often confused with social media marketing (Murdock 2012). Although social media marketing is widely adopted on social media platforms, it is more promotional and interfering than content marketing. While there are similarities between content and social media marketing, they have different processes, focal points and goals. Weinberg (2009) defines social media marketing as: 
the process that empowers individuals to promote their websites, products, or services through online social channels and tap into a much larger community that may not have been available via traditional channels. (p. 3)

Hillebrand (2014:9) argues that content marketing is used as an alternative to 'connecting with the users and building relationships with customers instead of simply informing about new products and promotions'. As early as 2008, Agichtein et al. (2008:183) argued that numerous social media activities revolve around content and that online communities have become one of the many emanations of social media. Much of the literature reveals that this phenomenon has since grown to include brands which, in order to stay relevant, must tap into the millions of social media conversations occurring in the array of social media communities (Kaplan \& Haenlein 2010; Smith, Fischer \& Yongjian 2012). Unlike much of the work in this area, which has focused on brand communities in social media networking sites from consumers' points of view (see, for example, Chi 2011; Dessart, Veloutsou \& Morgan-Thomas 2015; Tsimonis \& Dimitriadi 2014; Zaglia 2013), the focal point of this exploratory study is to gain a better understanding of content marketing practitioners' use of social media content communities to connect with the target audience. This study thus delineates content marketing's role in social media content communities to address the paucity of research and at the same time providing more clarity between content and social media marketing when building communities.

As a theoretical point of departure for social media brand communities, the researcher adopts the widely recognised and cited classification scale of social media types proposed by Kaplan and Haenlein (2010:63) that is based on consumers' social media presence and disclosure. A social media application such as Facebook is seen as a social networking site because of consumers' high level of social presence, selfpresentation and self-disclosure. Applications such as YouTube and Flickr, on the other hand, are classified as social media content communities because of less disclosure and presence, although consumers also share pictures, videos and other forms of media. A social networking site is also more friends-driven as opposed to the need for information in a social media content community. A social media content community's main objective is to share media content between users, allowing any content producer more flexibility to create and share content across multiple networks (Thompson 2011:463). While brands use content marketing on their own and partially owned media platforms, conversations around content in social media content communities offer interesting and alternative opportunities to build relationships and foster beneficial connections with consumers.

This argument is based on the findings generated through the investigation that addressed the following two main research questions:

- How do content marketing practitioners make use of social media content communities to connect with the target audience?
- In what way are content marketing techniques unobtrusive when it comes to building relationships with consumers in social media content communities?

This study made use of a directed, inductive qualitative content analysis of 51 practitioner documents relating to business-to-consumer (B2C) content marketing practices to provide evidence of a phenomenon that has not been widely investigated. In addition, incomplete conceptions about social media communities have been further refined, extended and enriched.

\section{Literature review}

The term 'content marketing' coined by Pulizzi (2010) from the Content Marketing Institute (CMI), is not new but it is still evolving. Defining content marketing has been challenging as its meaning changes depending on the context. Marketers are increasingly adopting content marketing to replace interruptive advertising and to attract more attention to the brand (Du Plessis 2015; Zahay 2014). Content marketing is ideal as it uses unobtrusive pulling and not pushing techniques to attract consumers to brand content (Liu \& Huang 2015). It furthermore implements theories of marketing communications, integrated marketing communication and relationship marketing (Cronin 2016:88). However, unlike promoting products or services, content marketing is a branding method that creates and distributes relevant and valuable brand content to entice and involve the target audience. Practitioners create and share brand stories online to make the target audience more familiar with the brand (Brieger 2013:6). Content marketing is often seen as resembling publishing, native advertising, inbound marketing and storytelling (Du Plessis 2015; Holliman \& Rowley 2014:270).

Numerous definitions of content marketing abound but thus far the CMI's definition of content marketing is still very popular which defines it as:

the marketing and business process for creating and distributing relevant and valuable content to attract, acquire, and engage a clearly defined and understood target audience - with the objective of driving profitable customer action. (Pulizzi 2012a)

However, content marketing has gradually expanded beyond this definition with scholars such as Du Plessis (2015) and Pazeraite and Repoviene (2016) acknowledging the complexities of the content marketing process which should be carefully managed. Pulizzi's (2012b:118) argument that authentic brand stories are the main focus of content marketing is supported as the theoretical lens through which content marketing is viewed for this study.

More recent studies about content marketing have approached it, among others, from angles such as business-to-business strategy (Holliman \& Rowley 2014), brand engagement (Vivero 2016), company branding (Koljonen 2016), its fundamentals (Du Plessis 2015), practical performance (Arhammar 2014), online marketing strategy (Augustini 2014), as a new trend in marketing practice (Wong \& Kee 
2015), customer satisfaction (Andaç, Akbiyik \& Karkar 2016), optimisation (Kose et al. 2016), digital channels (Banjo 2013), opportunities and challenges (Salojärvi 2016) and search advertisement effectiveness (Pazeraite \& Repoviene 2016). Although these studies consider social media as a tool that supplements a content marketing strategy, to the researcher's knowledge no study has specifically looked at content marketing's role in social media content communities to engage with the target audience in a more natural manner. Because content marketing follows and practices a 'consumercentred philosophy' (Kuş 2016:47), social media content communities allow for conversations around content, which a brand could use to resolve concerns, while the community members could also assist each other through user-generated content. In addition, more storytelling opportunities could connect consumers with the brand on a deeper emotional level. In this regard, Du Plessis (2015) argues that content marketing mirrors the natural occurrence and unobtrusiveness of content in private online media spaces while natural messages also add more warmth and a familiar brand voice in social media.

Much previous work has focused on describing virtual brand communities via social media, websites and blogs, in addition to reasons why consumers join them. Seminal work by Muniz (2001) defines a brand community as a:

specialized, non-geographically bound community, based on a structured set of social relationships among admirers of a brand. It is specialized because at its center is a branded good or service. (p. 142)

A study by Laroche et al. (2012) indicates that consumers join brand communities for various reasons which could benefit the brand in the long term. Consumers not only identify themselves with the brand, they also depict how they want to be identified by others in the same community. Being part of a community also enhances feelings of community which increases brand loyalty. In addition, some consumers search for content, opinions and advice while others do surveillance and want to exchange information (Muntinga, Moorman \& Smit 2011:16-17).

In another study Zhou et al. (2012) found that a sense of community leads to an emotional connection with the brand as consumers identify with it. A company should therefore strategically and continuously nurture relations within a brand community.

However, the evolvement of social media also gave rise to social media content communities where users consume, generate and share multimedia content on blogs, social bookmarking sites, and photo and video sharing communities because of a need for interest-driven participation (Thompson 2011:463). Some of the most popular content communities are currently focused on videos (YouTube), photos (Instagram and Flickr), bookmarking (del.icio.us), presentations (Slideshare) and audio (postcasts) (audio) (Content communities n.d.). Various community-driven question-and-answer portals, such as Quora and Yahoo Answers, also provide an alternative to finding answers without search engine searches but are not the focus of the study (Agichtein et al. 2008). Research by Chi (2011:51) indicates that users are more accepting of conversations in social media communities than advertising, as they are less intrusive. Social media has thus changed communities in that they are no longer only collected around a brand but also around social content interactions among the community members. Brands need to sustain these conversations with relevant and compelling content as part of a content strategy without interrupting the conversations. To engage consumers in a social media content community the content strategy should focus on identifying the type of content that would be interesting and relevant by understanding the target audience (Chauhan \& Pillai 2013:41). Consumers view brand content in their newsfeeds and choose to like, share or comment on them, which is a form of electronic word-ofmouth (eWOM). Research indicates that users engage most with brand posts that are consistent, interactive and vivid (Tafesse 2015:937). Engagement is a multi-dimensional concept, and various perspectives about what it entails are evident across different academic disciplines. Within the context of this study and building relationships, consumer engagement is defined by Van Doorn et al. (2010:254) as 'customers' behavioural manifestations that have a brand or firm focus, beyond purchase, resulting from motivational drivers'.

This behaviour is reflected in, among others, eWOM activity, recommendations, writing reviews, blogging and helping others. Online consumer-to-consumer interactions (eWOM) amplify reach and impact, while user-generated content reflect how engaged they are by interacting, sharing, uploading and creating content (Muntinga et al. 2011:16). However, Noble, Noble and Adjei (2012:476) warn about brands losing control and the possibility of negative eWOM in online social media communities, which should be carefully managed and responded to.

Because of the unobtrusive nature of content marketing, social media content communities could allow for nonpromotional information and interactions around a topic, which highlights the brand as a thought leader while gaining insight into the target audience. At the same time, a group of brand advocates could increase eWOM and thus engagement. A content community also provides both users and a brand the ideal opportunity to tell a story. The company could create content that humanises its brand and connects with the target audience by showing an understanding of their needs and problems. Similarly, users could co-create a story that reinforces a favourable perception of the brand (Johnston 2017).

\section{Methodology}

For this study, a directed content analysis of professional documents concerning B2C content marketing practices was done. Content analysis is a widely used and flexible method to analyse text data's patterns and frequency. A directed content analysis was a functional method for this study as research about content marketing in social media content 
communities is lacking and would benefit from further description (see Hsieh \& Shannon 2005:1277).

A total of 51 full-text copies of documents serving as best practice illustrations for digital marketing agencies' content marketing services were accessed online through search engine searches. The documents, in public domain, were identified and selected by using a purposive sample, a nonprobability sample procedure that uses specific selection criteria to fit the purpose of the study before elements are included (Daniel 2012:87). For this study, the criteria were that the documents had to include topical contributions concerning the use of social media for content marketing purposes. In addition, they had to convey practical information about using content marketing techniques for content communities. This study is exploratory in nature, and hence, 51 documents were deemed enough to provide a snapshot idea of current content marketing practices when it comes to social media content communities. The units of analysis were social artefacts (practitioner documents).

A qualitative data analysis approach by Miles and Huberman (1994) was followed for accurate data reduction to prepare the data and to ensure that only relevant material was used for the analysis. The directed content analysis approach entailed identifying key concepts in accordance with the literature as initial codes. The key concepts are development, process, conversations, engagement, platforms and channels, which were then appropriately labelled and condensed into three categories. Thereafter, operational definitions were developed for the three predetermined categories in accordance with the literature. After the initial manual review of the documents, they were imported into the QDA Miner qualitative data analysis software programme by Provalis Research. An electronic coding scheme was finalised by using the predetermined categories for text retrieval as a point of departure and highlighting similar data using different colours. All colour-coded data were then indexed into subcategories and labelled. Finally, summarised codes were checked for consistency and omissions as well as similarities and differences (see Hsieh \& Shannon 2005). The final code frame consisted of 25 individual codes located across the three main categories which were then interpreted inductively and conclusions drawn. The codes were interpreted on a manifest level (meaning visible in the text) followed by a latent level (considering the deeper meaning of the text) (Bengtsson 2016:9).

Similar to suggestions by Welsch (2002), the issue of coding reliability was addressed by following up the initial manual coding with coding via a qualitative data analysis software programme. This ensured that data were thoroughly interrogated. A computer programme-assisted analysis with, for example, QDA Miner software ensures higher reliability than human coding techniques (see Lewins \& Silver 2007).

\section{Findings}

Three categories with two subcategories respectively emerged from the data.

Table 1 illustrates the three main categories, number of cases, codes and frequency, which are discussed in more detail below. It can be inferred from this table that social media content communities are used in content marketing as an alternative way to engage the target audience.

Each category is explained in more detail below.

\section{Category 1: Building content communities}

Category 1 encompasses all findings relating to building communities around content. It constitutes $55.90 \%$ of the codes. Content communities allow the brand to build a community 'interested in its content' and who could also create more content to generate trust and credibility. Two subcategories also became evident, namely that of engagement and brand advocates. This category firstly illustrates that the main purpose of building content communities for content marketing is to enhance loyalty through creating and curating valuable content as gatekeepers 'to the best information on the industry available to them'. The brand must 'provoke' conversations by talking and socialising with the community through social listening and responding to all queries and concerns. This will indicate an understanding of consumers' needs. The content must be captivating enough to generate continuous conversations and could include many 'community elements' such as blog posts, newsletters, infographics, videos and images, to name a few. A widget 'to bring together social media posts' should also be available to the community.

Secondly, a community of brand advocates will also benefit the brand in the long term in that they constitute real fans. It is therefore important to have good knowledge about customers, including brand advocates, to develop a brand persona to which they can relate. Because the brand persona is 'a profile that a writer creates to embody the characteristics of the target audience for whom he or she is writing', it could serve as a 'framework' through which suitable content for the community could be created to humanise the brand and make it more visible. The brand's message will also be amplified if customers are motivated enough to create their own content, which will be available in their own networks.

TABLE 1: The three main categories and frequency in the data.

\begin{tabular}{|c|c|c|c|c|c|}
\hline \multirow[t]{2}{*}{ Category } & \multirow[t]{2}{*}{ Description } & \multirow[t]{2}{*}{ Frequency } & \multirow[t]{2}{*}{ Codes $(\%)$} & \multicolumn{2}{|c|}{ Cases } \\
\hline & & & & $n$ & $\%$ \\
\hline Building content communities & Community building around content & 184 & 55.90 & 23 & 45.10 \\
\hline Platform-specific content & Content that is tailored for specific community platforms & 73 & 22.20 & 23 & 45.10 \\
\hline Understanding channels & Content distribution and potential inconsistencies & 72 & 21.90 & 21 & 41.20 \\
\hline
\end{tabular}


Table 2 depicts the subcategories and codes for Category 1.

\section{Category 2: Platform-specific content}

Category 2 encompasses all findings relating to content that is tailored for specific platforms and not a 'one-size-fits-all' approach. It constitutes $22.20 \%$ of the codes. The platform of the content marketing message is the 'context' that should be considered as customer profiles are different on different platforms. The same content will therefore not be suitable for different content communities. Two subcategories also became evident, namely that of purpose and cross-form messaging. The category firstly illustrates that each 'piece of content' should have a purpose and a measurable goal to provide the necessary focus. Stories attract and retain customers and every platform's story plan should preferably form part of a documented content marketing strategy consisting of 'content pillars' to match consumers' interest. Each:

content pillar identifies a question, idea or type of information that will be useful to the audience, and each piece of content should align with a pillar to clarify what content types will work best.

The focused content will enhance the visibility of the content among the clutter. Content should be delivered at the right time for the most impact 'across channels by aligning personabased content with customers' digital body language'. By focusing on content quality 'value and engagement are created, not merely noise'.

Secondly, it is illustrated that cross-platform messaging should be true to the brand's essence to adequately represent and capture its unique attributes. It could also act as the 'basis for the emotional connection with customers' within the context of the reader. A more subtle approach includes non-promotional human stories with a tone of voice and style that 'act as glue' to enhance the relevance of the content on different platforms.

Table 3 depicts the subcategories and codes for Category 2.

\section{Category 3: Understanding channels}

Category 3 encompasses all findings relating to understanding channels and links to Category 2. It constitutes $21.90 \%$ of

TABLE 2: Category 1: Building content communities.

\begin{tabular}{lll}
\hline Subcategories & Engagement & Brand advocates \\
\hline Codes & Gatekeeper & Knowledge about customers \\
& Community elements & Customers create content \\
& Socialisation & Brand loyalty \\
& Useful content (problem-solving) & Brand persona \\
& Social listening & \\
\hline
\end{tabular}

TABLE 3: Category 2: Platform-specific content.

\begin{tabular}{lll}
\hline Subcategories & Purpose & Cross-platform messaging \\
\hline Codes & Timing & True to brand essence \\
& Measurable goal & Tone of voice and style \\
& Story plan as part of strategy & Human stories \\
& Content pillars & Non-promotional \\
\hline
\end{tabular}

the codes. This category, however, necessitates a separate discussion because it focuses more on integration of content for optimal reach and impact. Two subcategories also became evident, namely that of coherence and amplification.

The category firstly illustrates that to reach the target audience effectively in a social media content community, the channel should support the relevance of the message. The target audience is part of the community for a reason, and the content should address the audience's needs. Because brands typically use more than one channel, all channels should be coherent and unified when it comes to 'content touch points' to strengthen the message. The channels should also be linked to the main channel, which could be the brand's website or blog and be consistent with the brand's editorial strategy to humanise the brand. The content should form part of 'liquid ideas', which capture the imagination and generate eWOM but are still 'centred on the core brand story and experience'. In addition, 'liquid ideas' should reflect positively on the brand, although their impact cannot always be controlled. The channel should thus be understood to 'create a content ideology that matches consumer behaviour'.

Secondly, it has become evident that brands want to ensure optimal content consumption in social media content communities by having continuous open conversations around the content. The conversations are always unobtrusive because they deal with consumers' daily challenges and lives. The content should be 'evergreen' and up to date to ensure more return in the long term which could be financial, more brand awareness or demand generation (interest).

Table 4 depicts the subcategories and codes for Category 3.

\section{Discussion}

Although the findings cannot be generalised to all content marketing practices, the data provide sufficient evidence showing that social media content communities do play a role in content marketing, in addition to being present in virtual brand communities.

The first research question in this study sought to understand how content marketing practitioners make use of social media content communities to connect with the target audience. Findings suggest that practitioners strategically build content communities around content on different social media platforms to generate as much eWOM activity as possible, not only to build trust and credibility but also to achieve the greatest reach and impact (Muntinga et al. 2011:16-17). Practitioners thus provide compelling and relevant content to consumers who are really interested in

TABLE 4: Category 3: Understanding channels.

\begin{tabular}{lll}
\hline Subcategories & Coherence & Amplification \\
\hline Codes & Channel supports message & $\begin{array}{l}\text { Fostering dialogue (open } \\
\text { conversations) }\end{array}$ \\
& Liquid ideas & Content with more return \\
& Link to main channel & Optimal content consumption \\
& Consistence with editorial strategy & Evergreen and fresh \\
\hline
\end{tabular}


the content, as also put forward by Chauhan and Pillai (2013:40). The content is strategically planned for specific communities and for different channels based on a brand persona to which the target audience can relate. It is therefore important to understand the target audience and who the brand advocates are, as well as the best channels where they are present. (Du Plessis 2015:128). The brand then acts as a gatekeeper to generate conversations around the most recent and significant content in the industry that addresses consumers' needs, as was highlighted in a study by Andaç et al. (2016). In addition, brand advocates also augment messages by creating their own content. Consistent with the literature on engagement, consumers are motivated to become involved in eWOM activity because of relevance (Van Doorn et al. 2010). Because eWOM is anticipated in social media content communities, brands want content to create a buzz, but continuously use social monitoring tools to proactively respond to potential harmful conversations (Noble et al. 2012:479).

To answer the second research question, namely in what way content marketing techniques are unobtrusive, it was found that brands purposefully use non-promotional human stories carefully integrated on different social media platforms. Perhaps the most interesting findings are the activities with no promotional intrusion, which is consistent with the literature on content marketing. Consumers are truly interested in the content tailor made for the particular channels and are therefore drawn to it based on interest. Because the brand is able to connect emotionally with consumers, messages in social media content communities have the potential to become part of their daily lives (Zhou et al. 2012). The findings also support arguments by Du Plessis (2015:127) that natural messages also add more warmth and a familiar brand voice in social media to which consumers are paying attention. Kuş' (2016:47) arguments about a 'consumer-centred' community are important as the focus in social media content communities is on consumers' needs and not on the brand. These results further support the idea of the value of brands' unobtrusive participation in social media communities without alienating them with promotional content.

\section{Conclusion}

While exploratory in nature, this study offers several useful insights into how content marketing plays an important role in engaging with the target audience in an innate manner in social media content communities. This kind of engagement differs from the more intrusive nature of social media marketing. The findings have expanded understanding of how brands use social media communities to connect with the target audience, beyond having a presence in virtual brand communities. The findings also make several contributions to the existing literature. Firstly, it provides a clearer distinction between brand and content social media communities. Secondly, it extends conceptions about social media communities to include content communities and, thirdly, it provides sufficient evidence of how content marketing could benefit a brand by naturally becoming part of social media conversations.

The findings will be of interest to brand managers seeking alternative ways to connect with the target audience in social media. These findings add to the rapidly expanding field of content marketing by exploring a different area of practice. Further studies will have to continue to explore the significance of social media content communities also from a consumer perspective and with different methodologies. A limitation of the study is the non-probability type of sample. Findings can therefore not be generalised to the larger content marketing practitioner population. However, sufficient evidence in the data provides a snapshot idea of content marketing's role in social media content communities as well as areas that need further research.

\section{Acknowledgements Competing interests}

The author declares that she has no financial or personal relationships that may have inappropriately influenced her in writing this article.

\section{References}

Agichtein, E., Castillo, C., Debora, D. \& Gionis, A., 2008, 'Finding high-quality content in social media', in WSDM '08 Proceedings of the 2008 International Conference on Web Search and Data, Palo Alto, CA, February 11-12, 2008, pp. 183-194.

Andaç, A., Akbiyik, F. \& Karkar, A., 2016, 'Customer satisfaction factor in digital content marketing: Isparta Province as an example', International Journal of Social Science Studies 4(5), 124-135. https://doi.org/10.11114/ijsss.v4i5.1471

Arhammar, J., 2014, Content marketing: Practical enactments and performative ideas - An inquiry into what constitutes content marketing in Sweden, Unpublished dissertation, Uppsala University.

Augustini, M., 2014, Social media and content marketing as a part of an effective online marketing strategy, Unpublished dissertation, Masaryk University.

Banjo, O., 2013, B2B marketing communications in emerging markets content marketing in digital channels: A case study of the United Arab Emirates, Unpublished thesis, Oulu University of Applied Sciences.

Bengtsson, M., 2016, 'How to plan and perform a qualitative study using content analysis', Nursing Plus Open 2, 8-14. https://doi.org/10.1016/j.npls.2016.01.001

Brieger, C., 2013, Exploring new communication strategies for a global brandTransmedia storytelling and gamification, Published dissertation, Norwegian School of Economics, Norway.

Cawsey, T. \& Rowley, J., 2016, 'Social media brand building strategies in B2B companies', Marketing Intelligence \& Planning 34(6), 754-776. https://doi. org/10.1108/MIP-04-2015-0079

Chauhan, K. \& Pillai, A., 2013, 'Role of content strategy in social media brand communities: A case of higher education institutes in India', Journal of Product and Brand Management 22(1), 40-51. https://doi.org/10.1108/10610421311298687

Chi, H.-H., 2011, 'Interactive digital advertising vs. virtual brand community: Exploratory study of user motivation and social media marketing responses in Taiwan', Journal of Interactive Advertising 12(1), 44-61. https://doi.org/10.1080/ 15252019.2011.10722190

Cronin, J., 2016, 'Teach students to communicate a brand story with transmedia storytelling', Journal of Research in Interactive Marketing 10(2), 86-101. https:// doi.org/10.1108/jrim-01-2015-0004

Daniel, J., 2012, Sampling essentials: Practical guidelines for making sampling choices, Sage, Thousand Oaks, CA.

Dessart, L., Veloutsou, C. \& Morgan-Thomas, A., 2015, 'Consumer engagement in online brand communities: A social media perspective', Journal of Product \& Brand Management 24(4), 28-42. https://doi.org/10.1108/JPBM-06-2014-0635

Du Plessis, C., 2015, 'An exploratory analysis of essential elements of content marketing', in ECSM2015-Proceedings of the 2nd European Conference on Social Media, Portugal, July 9-10, Academic Conferences Publisher International, pp. 122-129.

Hillebrand, S., 2014, Content marketing in social networks, Unpublished dissertation, MBS - Universität Kassel.

Holliman, G. \& Rowley, J., 2014, 'Business to business digital content marketing: Marketers' perceptions of best practice', Journal of Research in Interactive Marketing 8(4), 269-293. https://doi.org/10.1108/JRIM-02-2014-0013 
Hsieh, H.F. \& Shannon, S.E., 2005, 'Three approaches to qualitative content analysis', Qualitative Health Research 15, 1277-1288. https://doi.org/10.1177/10497323 Qualitative

Johnston, M.R., 2017, How marketing must evolve: 19 leaders peer into content's future, viewed 07 March 2017, from http://contentmarketinginstitute.com/ 2017/02/marketing-evolve-contents-future/

Kaplan, A.M. \& Haenlein, M., 2010, 'Users of the world, unite! The challenges and opportunities of social media', Business Horizons 53(1), 59-68. https://doi. org/10.1016/j.bushor.2009.09.003

Koljonen, T., 2016, Content marketing's role in company branding and business, Master's thesis, International Business Management, (November), Lath University of Applied Sciences.

Kose, U., Hasan, A., Ahmet, D. \& Selcuk, S., 2016, 'A software system for intelligent mathematical optimization of content marketing', Proceedings of the 4th Virtual Multidisciplinary Conference, Zilina, Slovakia, December 12-16, 2016, pp. 131-136.

Kuş, O., 2016, 'The influence of cultural background on content marketing practices: The approach of Turkish and Lithuanian youth to the main components of content', Informacijos Mokslai 76, 45-60.

Laroche, M., Habibi, M.R. \& Richard, M.O., 2013, 'To be or not to be in social media: How brand loyalty is affected by social media?', International Journal of Information Management 33(1), 76-82. https://doi.org/10.1016/j.ijinfomgt.2012.07.003

Laroche, M., Habibi, M.R., Richard, M.O. \& Sankaranarayanan, R., 2012, 'The effects of social media based brand communities on brand community markers, value creation practices, brand trust and brand loyalty', Computers in Human Behavior 28(5), 1755-1767. https://doi.org/10.1016/j.chb.2012.04.016

Lewins, A. \& Silver, C., 2007, Using software in qualitative research: A step-by-step guide, Sage Publications, London.

Liu, H.W. \& Huang, H.C., 2015, 'Tradeoff Between Push and Pull Strategy: The Moderating Role of Brand Awareness', in H. Spotts (eds.), Marketing, Technology and Customer Commitment in the New Economy. Developments in Marketing Science: Proceedings of the Academy of Marketing Science. Springer, Cham, pp. 259-264.

Miles, M.B. \& Huberman, A.M., 1994, Qualitative data analysis: An expanded sourcebook, 2nd edn., Sage, Thousand Oaks, CA

Muniz, M.J., 2001, 'Brand community', Journal of Consumer Research 27, 412-432. https://doi.org/10.1086/319618

Muntinga, D.G., Moorman, M. \& Smit, E.G., 2011, 'Introducing COBRAs: Exploring motivations for brand-related social media use', International Journal of Advertising 30(1), 13-46. https://doi.org/10.2501/IJA-30-1-013-046

Murdock, T., 2012, Content marketing vs. social media marketing: What's the difference? viewed 11 July 2017, from http://contentmarketinginstitute. com/2012/02/content-marketing-vs-social-media-marketing/

Noble, C.H., Noble, S.M. \& Adjei, M.T., 2012, 'Let them talk! Managing primary and extended online brand communities for success', Business Horizons 55(5), 475483. https://doi.org/10.1016/j.bushor.2012.05.001

Pazeraite, A. \& Repoviene, R., 2016, 'Content marketing elements and their influence on search advertisement effectiveness: Theoretical background and practical insights', Management of Organizations: Systematic Research 75, 97-109. https:// doi.org/10.7220/MOSR.2335.8750.2016.75.7
Potgieter, L.M. \& Naidoo, R., 2017, 'Factors explaining user loyalty in a social mediabased brand community', South African Journal of Information Management 19(1), 1-9. https://doi.org/10.4102/sajim.v19i1.744

Pulizzi, J., 2010, New research: B2B content marketing benchmarks, trends and budgets, Content Marketing Research, Content Marketing Institute, viewed 02 March 2017 from http://contentmarketinginstitute.com/2010/09/b2b-content-marketing

Pulizzi, J., 2012a, Six useful content marketing definitions, viewed 02 March 2017, from $\mathrm{http}: / /$ contentmarketinginstitute.com/2012/06/content-marketing-definition/

Pulizzi, J., 2012b, 'The rise of storytelling as the new marketing', Publishing Research Quarterly 28(2), 116-123. https://doi.org/10.1007/s12109-012-9264-5

Rosenthal, B. \& Brito, E.P.Z., 2017, 'How virtual brand community traces may increase fan engagement in brand pages', Business Horizons 60(3), 375-384. https://doi. org/10.1016/j.bushor.2017.01.009

Salojärvi, S.H., 2016, Opportunities and challenges of content marketing as a way of digital marketing communications, Unpublished dissertation, Lappeenranta University of Technology.

Smith, A.N., Fischer, E. \& Yongjian, C., 2012, 'How does brand-related user-generated content differ across YouTube, Facebook, and Twitter?', Journal of Interactive Marketing 26(2), 102-113. https://doi.org/10.1016/j.intmar.2012.01.002

Tafesse, W., 2015, 'Content strategies and audience response on Facebook brand pages', Marketing Intelligence \& Planning 33(3), 927-943. https://doi.org/ 10.1108/MIP-07-2014-0135

Thompson, P., 2011, 'Social networking sites and content communities: Similarities, differences and affordances for learning', in Proceedings, Volume 2: Selected Papers on the Practice of Educational Communications and Technology, Jacksonville, FL, November 8-12, pp. 462-466.

Tsimonis, G. \& Dimitriadis, S., 2014, 'Brand strategies in social media', Marketing Intelligence \& Planning 32(2), 328-344. https://doi.org/10.1108/MIP-04-2013-0056

Van Doorn, J., Lemon, K.N., Mittal, V., Nass, S. \& Pick, D., 2010, 'Customer engagement behaviour - Theoretical foundations and research directions', Journal of Service Research 13(3), 253-266. https://doi.org/10.1177/1094670510375599

Vivero, D.P., 2016, The effect of educational content marketing on Facebook brand engagement, Unpublished dissertation, Católica Lisbon School of Business \& Economics.

Weinberg, T., 2009, The new community rules: Marketing on the social web, United States, O'Reilly.

Welsch, E., 2002, 'Dealing with data: Using NVivo in the qualitative data analysis process', Forum Qualitative Social Research 33(2), Art 26, viewed 07 March 2017 , from http://www.qualitative-research.net/index.php/fqs/article/view/865/

Wong, A. \& Kee, A., 2015, 'The review of content marketing as a new trend in marketing practices', International Journal of Management, Accounting and Economics 2(9), 1055-1064

Zaglia, M.E., 2013, 'Brand communities embedded in social networks', Journal of Business Research 66, 216-223. https://doi.org/10.1016/j.jbusres.2012.07.015

Zahay, D., 2014, 'Beyond interactive marketing', Journal of Research in Interactive Marketing 8(4). https://doi.org/10.1108/JRIM-08-2014-0047

Zhou, Z., Zhang, Q., Sue, C., \& Zhou, N., 2012, 'How do brand communities generate brand relationships? Intermediate mechanisms', Journal of Business Research 65 890-895. https://doi.org/10.1016/j.jbusres.2011.06.034 